\title{
Abismo ou continuidades? Polêmicas sobre o tupi pré-colonial e a língua geral disseminada pelos jesuítas
}

\author{
Abysm or continuities? Polemics surrounding \\ pre-colonial Tupi and the 'general language' \\ disseminated by the Jesuits
}

\author{
Jânia Martins Ramos \\ Professora de lingüística da \\ Universidade Federal de Minas Gerais/UFMG \\ Rua Professor Ziller, 317 \\ 30730-200 Belo Horizonte - MG - Brasil \\ ramosjan@zaz.com.br \\ Renato Pinto Venâncio \\ Professor de demografia histórica da \\ Universidade Federal de Ouro Preto/UFOP \\ Rua Professor Ziller, 317 \\ 30730-200 Belo Horizonte - MG - Brasil
}

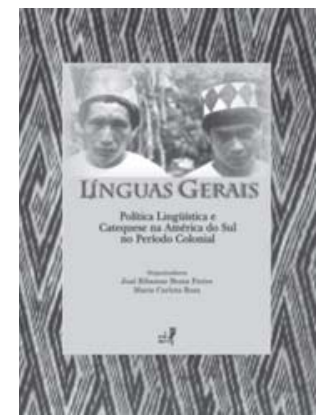

José Ribamar Bessa Freire; Maria Carlota Rosa (org.) Línguas gerais: política lingüística na América do Sul no período colonial.

Rio de Janeiro: Ed. UERJ, 2000. 209 p.

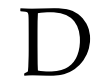
esde o século XIX, quando se registram os primeiros estudos filológicos a respeito do tupi, surgiu uma questão que até hoje gera polêmicas. Tal debate pode ser sintetizado na seguinte questão: em que medida os escritos missionários são testemunhos confiáveis, do ponto de vista lingüístico, a respeito do português falado antes de 1500 ? Diante de tal questão, surgiram duas correntes interpretativas. A primeira defende que os jesuítas, ao sistematizarem a gramática do idioma indígena, teriam atribuído a ela uma estrutura semelhante à dos idiomas consagrados em sua sociedade de origem (latim, português, espanhol etc.). Dessa forma, haveria um abismo entre o tupi pré-colonial e a língua geral veiculada nos aldeamentos da Companhia de Jesus. A outra corrente sustenta o predomínio da continuidade entre as duas estruturas lingüísticas. O mérito do livro de Freire e Rosa é o de recuperar esse debate e de fazê-lo em uma escala continental, pois a polêmica aqui citada também se registra no México, Peru e em outros países latino-americanos.

No primeiro capítulo, Yonne Leite defende que, no caso da Arte da gramática (1595), de autoria de José de Anchieta, teriam predominado continuidades e não rupturas, e o uso do latim como referencial não teria impedido a caracterização dos "processos fonológicos, morfológicos e sintáticos ... do tupi ancestral" (p. 23). Focalizando fenômenos que considera tipologicamente cruciais, compara-os com resultados de estudos recentes sobre línguas indígenas, e avalia não se poder afirmar que Anchieta tenha "simplificado a língua mais usada na costa do Brasil" (p. 23). O capítulo seguinte, de Luciana Gimenes, sustenta que, "paralelamente às descrições calcadas no modelo latino, teria havido outras". É na trilha de viajantes e cronistas portugueses, franceses e italianos que a autora procura novas pistas. Registra-se, 
nesse texto, uma grande variação entre um testemunho e outro, sugerindo assim que "a situação de contato entre culturas e línguas diferentes estimularia o aparecimento de especulações sobre a língua/linguagem com base na consciência do falante, nem sempre intermediada por uma metalinguagem predefinida" (p. 39).

Como se vê, o antigo debate sobre a relação entre o tupi e a língua geral está longe de esmorecer. O terceiro capítulo, assinado por Consuelo Alfaro Lagorio, investiga os aspectos normativos das políticas lingüísticas. Em fins do século XVI, um concílio episcopal, reunindo representantes do conjunto da América espanhola, defende a uniformidade dos catecismos. O idioma a ser adotado é um tema central nas discussões. Defende-se ora o castelhano, ora a língua geral - esta última baseada no quechua, idioma indígena escolhido entre vários, pois antes mesmo da colonização desempenhava um papel de língua geral no império inca. $\mathrm{O}$ autor não deixa dúvidas a respeito da posição defendida:

o modelo arquetípico da língua quechua se fez a partir da variante cusquenha, que ideologicamente é representada como a língua do centro do poder e das elites. Porém, devia passar por processos de depuração das "esquisitices", formas arcaizantes e obscuridades. Assim, o processo de planejamento produziu uma língua escrita que não se identificava totalmente com qualquer das línguas faladas pelos povos andinos (p. 50).

No quarto capítulo, de Cristina Altman, empreende-se um estudo comparativo entre as línguas gerais da América espanhola e portuguesa. Com sensibilidade, a autora procura aproximações entre as duas linhas interpretativas apresentadas:

Parece que a transferência do molde latino para as gramáticas das línguas gerais provocou dois efeitos aparentemente paradoxais. Se, de um lado, permitiu o acúmulo de dados descritivos a partir de uma mesma metalinguagem, de outro favoreceu o acúmulo de "anomalias"... O desafio de conciliar finalidade pedagógica da gramática e sua adequação descritiva promoveu a concepção de uma estruturação lingüística autônoma e relativa (p. 75-6).

Portanto, não teria havido nem uma total continuidade nem uma total ruptura, mas sim uma autonomia relativa, a ser identificada através de pesquisas específicas.

Maria Cândida D. M. Barros, no quinto capítulo, explora a dicotomia tupi do litoral versus tapuia do interior. Tal contraposição era registrada desde o século XVI, de certa forma reproduzindo antigas rivalidades pré-coloniais. Os jesuítas valorizaram as tradições lingüísticas dos primeiros povos, ao mesmo tempo em que consideravam as últimas 'travadas' e de impossível sistematização. Ora, ao fazerem essa escolha, acabaram por promover uma tupinização de povos tapuias, localizados em aldeados dirigidos pelos inacianos, principalmente na região amazônica. Tal processo há muito é discutido em textos de etnologia e história. A contribuição da lingüista é a de identificar, na documentação colonial, o surgimento da "língua geral verdadeira" em contra-posição 
à "língua geral corrupta". As transformações registradas chegam a ponto de não habilitar os falantes da última variedade a compreender as pregações religiosas que recorriam à primeira variante. $\mathrm{O}$ que sugere pistas interessantes para o entendimento do que teria ocorrido na passagem entre o tupi pré-colonial e a primeira língua geral dos jesuítas.

O sexto capítulo, de autoria de Luiz C. Borges, também explora a riqueza da Língua Geral Amazônica. O texto seguinte, assinado por Maria Carlota Rosa, investiga, com erudição, o papel das línguas gerais no processo de colonização. Esse papel estratégico levava a avaliações diferenciadas, resultantes dos interesses em jogo. Ora a língua geral era avaliada como "tosca e sem palavras", ora como "língua copiosa como a grega" (p. 133). Esse vínculo ambíguo com o poder contribuiu para seu declínio, principalmente após a implementação da política pombalina, que expulsou os jesuítas do espaço colonial e decretou a obrigatoriedade do uso do português.

Nos dois capítulos subseqüentes, Roland Schmidt-Riese e Uli Reich analisam o nheengatu, variedade amazônica da língua geral. O primeiro autor apresenta uma síntese da discussão teórica sobre mudança lingüística, chegando a quatro noções: imposição, empréstimo, reestruturação e reoperacionalização. Com base neles, delineia sete cenários que visam retratar etapas da evolução do nheengatu, desde o período pré-colonial até nossos dias. Estes cenários constituiriam "uma releitura das informações relativas à história lingüística da Amazônia, colhidas principalmente em Bessa Freire (1983)" (p. 157). Já Uli Reich compara realizações de marcas de Caso do tupinambá clássico, apresentado na gramática de Anchieta, com traços do atual nheengatu. A partir da proposta de Dowty (1991) sobre papéis semânticos, aponta uma mudança tipológica: "de sistema ativo/inativo para nominativo/ acusativo" (p. 173), acrescentando evidências convincentes.

Rosa Maria Fonini Monserrat apresenta valiosos resultados de uma pesquisa realizada em 1970 na Biblioteca Nacional e no Museu Nacional. Aponta fontes bibliográficas sobre o tupi médio (século XVIII), agrupadas como "datadas, não datadas e textos" (dois manuscritos e duas cópias impressas de manuscritos), além de indicação de fontes sobre vocabulário. Acrescenta anotações sobre o sistema sonoro do tupi do referido período. Por fim, José Ribamar Bessa Freire aponta para a importância da presença da língua geral na região amazônica, mesmo após a Independência do Brasil, concluindo: “Coube, portanto, ao estado neobrasileiro a tarefa de completar o processo de portugalização da Amazônia".

O conjunto dos textos apresentados sintetiza, com muita propriedade, o estado atual dos debates a respeito das línguas gerais do Novo Mundo. A impossibilidade de termos acesso a testemunhos anteriores a 1500 em muito dificulta as conclusões. Isso, longe de desmerecer o livro, o transforma em um rico manancial de sugestões de pesquisa.

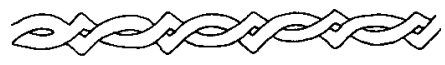




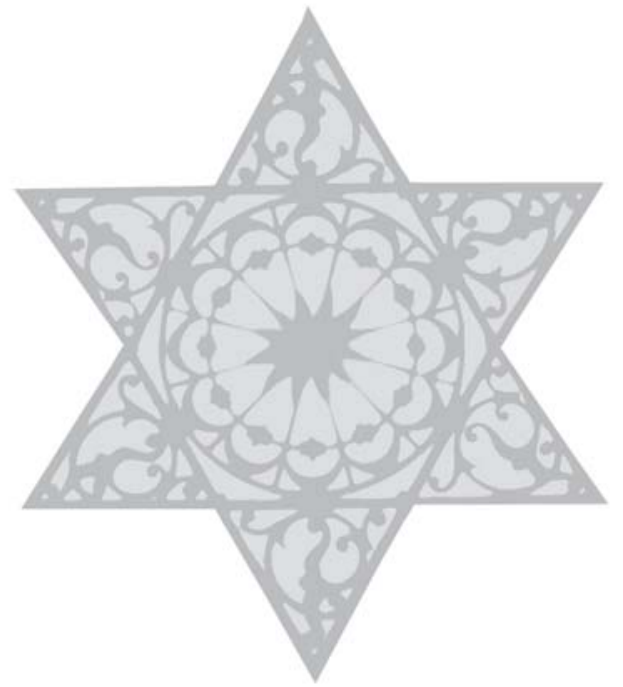

